\title{
The Importance of Energy Balance
}

\author{
James O Hill, Holly R Wyatt and John C Peters
}

Anschutz Health \& Wellness Center, University of Colorado, Aurora, Colorado, US

\begin{abstract}
Globally, bodyweight and obesity are rising in both the developing and developed world. To maintain a stable bodyweight, energy intake must, over time, exactly equal energy expenditure, a state known as energy balance. An understanding of the physiologic control of energy balance may be useful for designing interventions to tackle the obesity epidemic worldwide. Obesity occurs when the body's energy balance is positive (i.e. when energy intake exceeds energy expenditure). Human physiology is biased towards maintaining energy balance at high levels of energy intake and expenditure. As a result, strategies to combat obesity should include a focus on increasing physical activity along with strategies for modifying food intake. An understanding of energy balance leads to the conclusion that prevention of weight gain should be easier than treatment of obesity. Components of energy balance are interdependent, and weight loss requires major behaviour changes, which trigger compensatory decreases in energy expenditure that facilitate weight regain. Prevention of weight gain can be accomplished by smaller behaviour changes. In addition to being easier to sustain than larger behaviour changes, smaller ones produce less compensation by the energy balance regulatory system. It has been estimated that relatively small changes in energy intake and expenditure totaling $100 \mathrm{kcal}$ per day could arrest weight gain in most people. Interventions that advocate small changes have shown promising levels of success.
\end{abstract}

\section{Keywords}

Energy balance, obesity, physical activity

Disclosure: James 0 Hill has advisory roles for General Mills, MCDonald's, McCormick, and Wrigley; grant support from the American Beverage Association (ABA); and research support from GI Dynamics and Novo Nordisk. Holly R Wyatt has grant support from the ABA; research support from GI Dynamics and Novo Nordisk; and advisory roles for Eisai, Retrofit, and Wellspring. John C Peters has grant support from the ABA.

Received: 5 March 2013 Accepted: 26 April 2013 Citation: European Endocrinology, 2013;9(2):111-5 DOI:10.17925/EE.2013.09.02.111

Correspondence: James O Hill, Anschutz Health and Wellness Center, 12348 E. Montview Blvd. Mailstop C263, Aurora CO 80045, US. E: james.hill@ucdenver.edu

Support: The publication of this article was supported by The Coca-Cola Company. The views and opinions expressed are those of the authors.

Obesity is a growing problem with many associated health risks and associated costs. ${ }^{1,2}$ During 1971 to 2000 , the prevalence of obesity in the US increased from $14.5 \%$ to $30.9 \% .{ }^{3}$ In the US, more than $37 \%$ of adults and almost $17 \%$ of youths were obese in 2009-10. ${ }^{4}$ Currently over 1.1 billion adults worldwide are overweight, and of these, 312 million are obese. ${ }^{5}$ Analysis of data from the US Longitudinal (CARDIA study) ${ }^{6}$ and cross-sectional (NHANES) ${ }^{7}$ studies to determine the distribution of weight gain over time, found that the average US adult is gaining $0.5-1 \mathrm{~kg} / \mathrm{year}^{8}{ }^{8}$ This article will examine the concept of energy balance and its relevance in combating the obesity epidemic.

\section{The Concept of Energy Balance}

The concept of energy balance is based on the fundamental thermodynamic principle that energy cannot be destroyed, and can only be gained, lost, or stored by an organism. Energy balance is defined as the state achieved when the energy intake equals energy expenditure. This concept may be used to demonstrate how bodyweight will change over time in response to changes in energy intake and expenditure. When the body is in energy balance, bodyweight is stable.,10 Humans take in energy through the intake of food and drink, and expend energy through the resting metabolic rate (RMR) - the thermic effect (TEF) of food and physical activity. The RMR is the energy expenditure required for maintaining normal body functions and homeostasis. The RMR is proportional to body mass, in particular fat-free mass. TEF refers to the energy required to absorb, digest, and metabolise the food consumed and typically accounts for 8-10\% of daily energy expenditure. The energy expended due to physical activity (EEact) accounts for energy that is expended in addition to the RMR and TEF, including voluntary exercise, shivering, postural control, and voluntary movement. It is calculated by multiplying the energy expenditure of an activity by the time spent performing it, and is the most variable component of energy expenditure. ${ }^{10}$ The more sedentary the individual is, the lower the effect of physical activity. This may be as low as 100 calories per day, whereas elite athletes may expend 3,000 calories per day of physical activity. The decline in energy expenditure that occurs with advancing age is mainly the results of declining lean body mass, which reduces TEF and EEact.

Disturbances in energy balance cause changes in body mass, although the timeframe over which this occurs varies between individuals and may explain the large interindividual response to weight-loss interventions. A positive energy balance, in which energy intake exceeds expenditure causes weight gain, with $60-80 \%$ of the resulting weight gain being attributable to body fat. ${ }^{11}$ In negative energy balance, when energy expenditure exceeds intake, the resulting loss in body mass is also accounted for by $60-80 \%$ body fat.

It is commonly assumed that energy intake and energy expenditure can be independently modified, through changes in food intake and 


\section{Figure 1: Continued Weight Gain in the Population According to the Concept of Energy Balance ${ }^{14}$}

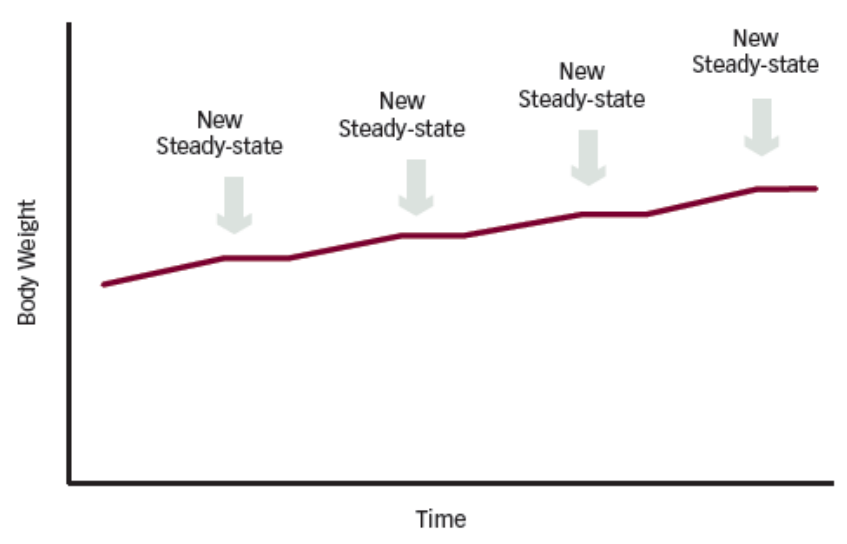

Figure 2: Relationship between Energy Balance and Physical Activity Level ${ }^{10}$

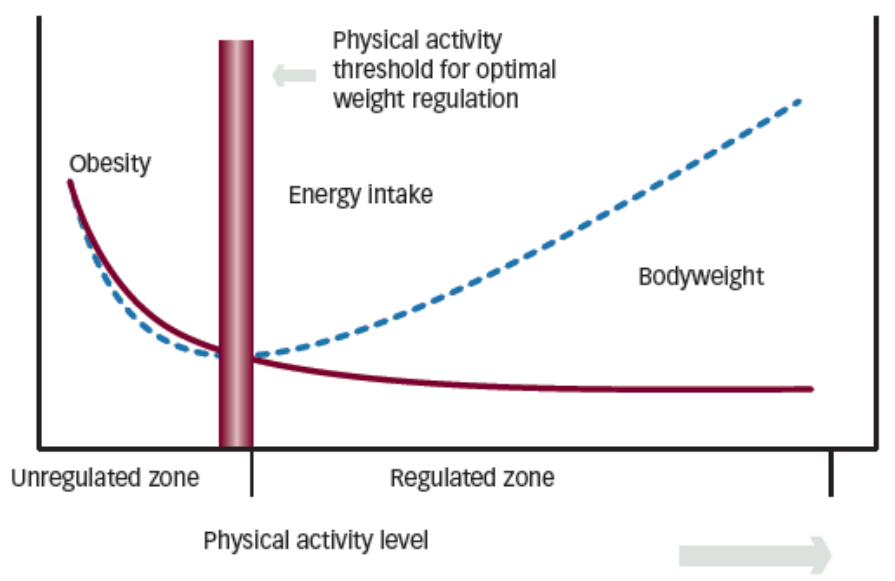

physical activity, to achieve energy balance. However, energy input and expenditure are interdependent and regulated at several levels. This involves a complex physiologic control system, which involves afferent neural and hormonal signals reaching the hypothalamus, with resultant efferent projections of the autonomic nervous system innervating the muscles, viscera, and adipose tissue. ${ }^{12}$ As a result of this physiologic control, components of energy intake and expenditure cannot be altered without compensatory changes in the other. The components of energy balance influence each other and serve to maintain a constant body mass. For example, when calorie intake is reduced, the body responds by both stimulating hunger and reducing the RMR so that less energy is expended. ${ }^{13}$ Similarly, an increase in EEact could result in increased hunger or reductions in physical activity at other times during the day. ${ }^{9}$ In energy balance terms, the compensation in response to positive energy balance seems to be weaker that the compensation in response to negative energy balance.

Despite this internal control system, the majority of adults gain weight over time. Consuming excess energy does not result in continuous weight gain, since the weight gain is accompanied by an increase in energy expenditure that leads to a steady state of energy balance at this new, slightly higher bodyweight. However, it is likely that this increased energy requirement eventually leads to increased energy intake, creating a 'ratchet effect' whereby a small, consistent positive energy balance results in a gradual weight gain over time (see Figure 1). ${ }^{14}$

Evidence suggests that it is more difficult to maintain energy balance in the modern environment than it was in the past. However, the weight gain that has actually occurred in the last decades is less than that predicted by changes in energy intake and expenditure. Using estimates of food intake increases and physical activity decreases from 1971 to 2000 , it has been calculated that US adults have experienced a degree of positive energy balance sufficient to result in a 30 - to 80 -fold increase in weight gain during that period. It is therefore evident that physiologic processes have caused adaptations that serve to help maintain energy balance. ${ }^{10}$

Theoretically, energy balance may be achieved at low or high levels of energy expenditure. However, it has been hypothesised that energy balance may be easier to achieve at high levels of energy expenditure, known as high-energy throughput. ${ }^{10}$ In the 1950s, cross-sectional studies found that energy intake was better matched to energy expenditure when people were physically active..$^{15}$ Furthermore, studies in rats found that the relationship between food intake and energy expenditure was only linear within certain limits. ${ }^{16}$ In rats, the matching of energy intake and expenditure was inaccurate at low or high levels of physical activity. The same observation was made in human studies: food intake did not drop when energy demand declined. On the basis of these observations, it has been proposed that a minimum threshold of either physical activity or energy throughput may exist. Above this threshold, termed the 'regulated zone', energy intake is raised to meet high energy expenditure. As a result, adaptive adjustments in energy intake and expenditure to achieve balance may be very sensitive in this zone. At low energy throughput, the 'unregulated zone', energy intake and expenditure are only weakly sensitive to each other. The unregulated zone is difficult for most people to sustain, and the result is weight gain, which returns the system to a high-energy throughput (see Figure 2). ${ }^{10,15}$ Over the last century, the energy throughputs of Western human lifestyles have declined, pushing the majority of people into the unregulated zone. Increasing physical activity for individuals who are in the unregulated zone should lead to weight loss since the compensation from food intake is not likely to be complete. ${ }^{17,18}$

\section{The Role of Physical Activity in Energy Balance}

Strategies to combat obesity must target both energy input and expenditure, which includes food intake and physical activity. A recent report concluded that resting metabolism does not play a significant role in weight gain and that physical activity is a more important factor. ${ }^{19}$ Some authors have attributed the weight gain in the US population exclusively to the increased intake of food, arguing that leisure time physical activity has remained stable over the decades in which obesity rates increased. ${ }^{20}$ However, this interpretation dismisses the decline in both lifestyle and occupational physical activity that has occurred over the past century. ${ }^{10}$ This continued decline in daily physical activity energy expenditure has created a 'permissive' situation in which any excess calorie intake is likely to promote weight gain (i.e. the unregulated zone). Weight gain in individuals maintaining a greater level of physical activity energy expenditure is less than among sedentary individuals, supporting the idea that higher levels of energy flux are protective against positive energy imbalance. Multiple studies have demonstrated that a high level of physical activity is associated with less weight gain over time, while lower levels of physical activity are associated with higher weight gain over time (see Table 1), ${ }^{6,721-24}$ 
Table 1: Summary of Studies of Physical Activity and Weight Gain

\begin{tabular}{ll} 
Study Name & Study Design \\
\hline $\begin{array}{l}\text { The Coronary Artery Risk } \\
\text { Development in Young Adults } \\
\text { (CARDIA) study }\end{array}$ & $\begin{array}{l}\text { Prospective, longitudinal study, } \\
3,554 \text { men, 20 years }\end{array}$ \\
\hline Finnish Twin cohort study & $\begin{array}{l}\text { Cohort study, 146 twin pairs, } \\
30 \text { years }\end{array}$
\end{tabular}

Aerobics Center Longitudinal Study

PRIME study

NHANES-I epidemiologic follow-up study

Healthy Worker project

Doetinchem cohort study

EPIC-PANACEA
Clinic-based cohort study, 2,501 healthy men, 5 years

Longitudinal cohort study, men aged $50-59$ years, 5 years
Cohort study, 3,515 men and 5,810 women aged $25-74$ years. 10 years

Cohort study 1,639 male 1,913 female employees 2 years

4,944 participants of the Doetinchem Study, 5 years

\section{Results}

Men with high PA gained 2.6 fewer $\mathrm{kg}$ (0.15 BMl units/yr vs 0.20 with low PA) and women with high PA gained 6.1 fewer $\mathrm{kg}$ (0.17 BMI units/yr vs 0.30) with low PA

In 42 twin pairs with discordant PA, the mean weight gain from was $5.4 \mathrm{~kg}$ less in the active compared with inactive twins $(p=0.003)$

Daily PA was inversely related to weight gain. A shift from a Iow PA to a moderate or high PA was necessary for weight loss over time. Men with initially the lowest PA had the greatest benefit from increasing activity

$\mathrm{BMI}$, was inversely associated with PA spent in getting to work and practice of highintensity recreational activities. Men who regularly walked or cycled to work had a mean BMI $0.3 \mathrm{~kg} / \mathrm{m}^{2}$ lower than those who did not expend energy in getting to work

Cross-sectional analysis, 125,629 men and 280,190 women, 8 years
Recreational PA was inversely related to bodyweight. The estimated relative risk of major weight gain for those with low PA survey compared with those with high PA was 3.1 in men and 3.8 in women

Increased exercise, either walking or highintensity activity, predicted decreases in bodyweight in women and men $(1.76 \mathrm{lb}$ and $1.39 \mathrm{lb}$, respectively, for each session increase per week)

Those who increased PA had less gain in bodyweight (-280 g). These effects were sustained (although not significantly) for 5 years

A one-category difference in the PA index was inversely associated with a difference of $0.18 \mathrm{~kg} / \mathrm{m}^{2}$ in mean BMl in men and $0.31 \mathrm{~kg} / \mathrm{m}^{2}$ in women

\section{Reference}

Hankinson et al., 20106

Waller et al., $2008^{24}$

Di Pietro et al., $2004^{44}$

Wagner et al., $2001^{45}$

Williamson et al., 19937

French et al., 199422

May et al., 201023

Besson et al., $2009^{21}$

BMI = body mass index; EPIC-PANACEA = European Prospective Investigation into Cancer and Nutrition-Physical Activity, Nutrition, Alcohol, Cessation of Smoking, Eating Out of Home and Obesity; NHANES = National Health and Nutrition Examination Survey; PA = physical activity.

The Prospective Epidemiological Study of Myocardial Infarction (PRIME) Study is a prospective study conducted in a cohort of 50 to 59 -year-old men, to evaluate the contribution of risk and genetic factors to the development of coronary heart disease.

Urbanisation, industrialisation, and use of mechanised transportation have lead to a general decrease in physical activity. While leisure time physical activity has remained fairly constant since $1988,{ }^{25}$ physical activity in terms of lifestyle has declined significantly. A study of an Old Order Amish community found that the average number of steps per day taken by men in the community was 18,425 versus 14,196 for women. ${ }^{26}$ By contrast, in Colorado, the average male takes 6,733 steps per day, and the average female takes 6,384 steps per day, ${ }^{27}$ a difference in daily energy expenditure of 400-600 kcal per day. It has been estimated that over the last 50 years in the US, daily occupationrelated energy expenditure has decreased by more than 100 calories as modern sedentary lifestyles require much less energy expenditure than in the past.

As physical activity has decreased, bodyweights have increased, which is accompanied by a corresponding increase in energy expenditure. In fact, it has been suggested that becoming obese is the body's way of increasing energy expenditure to achieve energy balance in an increasingly sedentary lifestyle. ${ }^{10}$
In terms of our understanding of energy balance, individuals with low levels of physical activity are at greater risk of positive energy balance and obesity compared with those with higher levels of physical activity. Those with a low level of physical activity have trouble achieving energy balance because they have to restrict their food to match their energy intake to a low level of energy expenditure. This hypotheses is supported by data that shows that at low levels of physical activity, the energy intake does not change quickly and accurately to reflect the changes in expenditure, resulting in a tendency to gain weight. ${ }^{28}$ In a study of six normal weight men in a whole-room calorimeter, reducing the level of physical activity from 1.8 to 1.4 X RMR did not induce a compensatory reduction in appetite or hunger, resulting in positive energy balance and weight gain, seen as a net gain in fat (see Figure 3). ${ }^{29}$ The authors concluded that varying the level of activity within the sedentary range has a significant effect on energy balance.

Fewer studies have investigated the primary prevention of weight gain as a function of increasing physical activity in contrast to either weight loss or secondary weight gain following weight reduction. In contrast to 
Figure 3: Mean Cumulative Fat Balance for Men During Active and Sedentary Regimens ${ }^{29}$

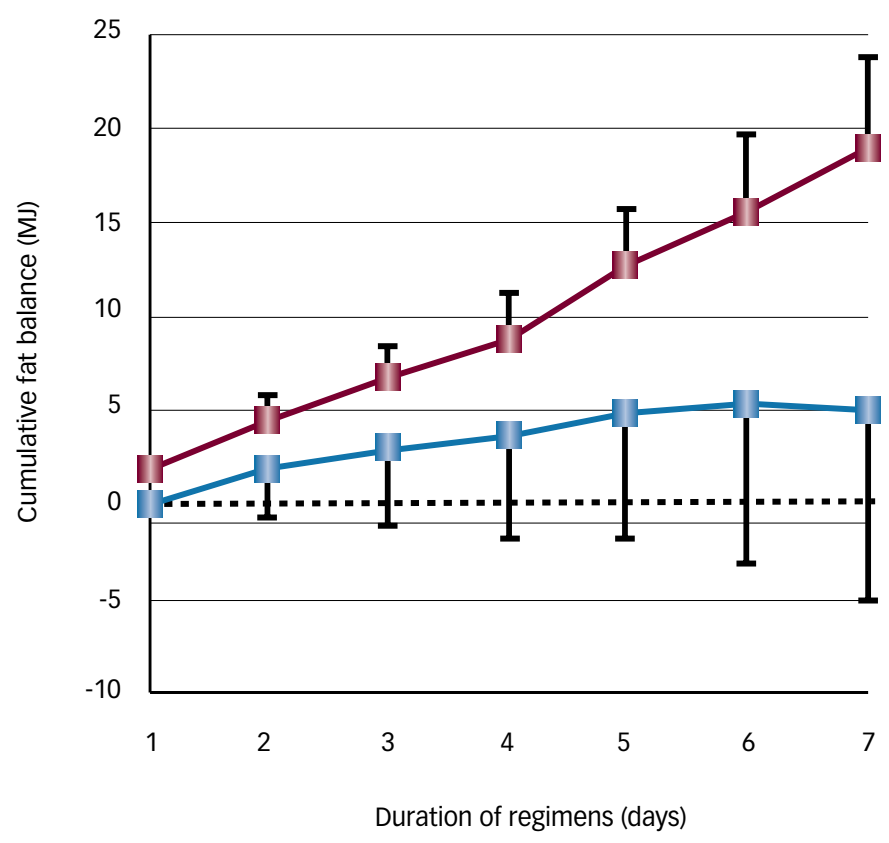

11 Sedentary regimen

11 Active regimen

studies showing an increase in food intake to maintain energy balance with the addition of exercise, a study has suggested that adding small amounts of activity to daily lifestyles reduces the weight gain that many people in the US are experiencing year after year. ${ }^{30}$

In summary, there are clear benefits associated with increasing physical activity among the sedentary. A healthy weight is best maintained with a relatively high level of physical activity and a high energy intake. This does not mean that the need to control food intake should be forgotten. Strategies aimed at increasing energy expenditure while controlling food intake should form the basis of interventions to combat obesity, rather than focusing solely on food restriction.

\section{Strategies to Combat the Obesity Epidemic}

The evidence discussed above suggests that strategies to reduce the obesity epidemic should aim to push the population into the regulated zone of energy balance, and this can be achieved through an increase in physical activity. Interventions and recommendations that do not take into account both energy intake and expenditure tend to be unsuccessful in combating obesity in the long term. ${ }^{31}$ However, the majority of current weight loss interventions place the emphasis on food restriction rather than energy balance. Regimens involving food restrictions tend to cause compensatory decreases in energy expenditure ${ }^{32}$ and an increase in hunger. ${ }^{33} \mathrm{~A}$ study of the National Weight Control Registry found that successful long-term weight loss maintainers (defined as average weight loss of $30 \mathrm{~kg}$ for an average of 5.5 years) engage in high levels of regular physical activity. ${ }^{34}$

Strategies to prevent weight gain are more likely to be successful in the long term compared with strategies to promote weight loss because the physiologic systems involved in energy balance system respond more strongly to negative energy balance than to the prevention of positive energy balance. ${ }^{32}$ Weight loss interventions trigger compensatory mechanisms to maintain energy balance. Since loss of body mass results in a decline in RMR, a $10 \%$ weight loss can result in a reduction in calorie requirement of 170-250 kcal per day, and a $20 \%$ weight loss requires a reduction of $325-480 \mathrm{kcal}$ per days. ${ }^{14}$ Furthermore, only small changes in behaviour are required to prevent weight gain whereas large changes are required to produce sustained weight loss.

We are much more successful in producing weight loss than in maintaining it over the long term..$^{35}$ Weight loss can be achieved through temporary changes in either diet or physical activity but longterm weight loss maintenance requires permanent changes in both diet and physical activity. Since people are better at making temporary changes than permanent ones, most people who do achieve weight loss goals regain the weight lost over time.

In a review of the long-term outcomes of calorie-restricting diets, it was found that one-third to two-thirds of dieters regain more weight than they lost on their diets. ${ }^{36}$ It is therefore clear that current paradigms of weight control are unsuccessful and better strategies might be developed with a better understanding of the physiologic processes underlying energy balance.

The change in energy balance required to prevent primary weight gain is relatively small: a mathematical modeling approach was applied to US population models and concluded that the obesity epidemic could be explained by an average daily energy imbalance between intake and expenditure of about $10 \mathrm{kcal} .^{37}$ Hill estimated that the median weight gain of the population of 0.5 to $1 \mathrm{~kg}$ a year over the last two decades can be accounted for by a positive energy balance of $15 \mathrm{kcal}$ per day. ${ }^{8}$ At the 90th percentile of weight gain, this was $50 \mathrm{kcal}$ per day. Based on the assumption that excess energy is stored with $50 \%$ efficiency, it was suggested that by reducing positive energy balance by $100 \mathrm{kcal} /$ day by a combination of reductions in energy intake and increases in physical activity, weight gain in $90 \%$ of the adult population could be prevented. This approach has been applied to US children and it was concluded that consistent behavioural changes averaging 110 to $165 \mathrm{kcal}$ per day may be sufficient to counterbalance the energy gap. ${ }^{38}$

Public health interventions may benefit from changing energy balance by using a specific quantifiable behavioural goal. However, changing any behaviour is difficult and using a small-changes approach is useful for promoting incremental improvements that build self-efficacy along the way. Prospective studies have shown that small changes in diet and lifestyle can produce sustained effects on bodyweight. ${ }^{39} \mathrm{~A}$ task force consisting of members of the American Society for Nutrition, the Institute of Food Technologists, and the International Food Information Council concluded that a small-changes approach, aimed at helping people make conscious small lifestyle changes, could be useful in addressing obesity. ${ }^{40}$

Based on the concept of small-changes approaches, the America on the Move programme advocates walking 2,000 more steps each day and eating $100 \mathrm{kcal}$ less each day (www.americaonthemove.org). It has been demonstrated that providing electronic step counters (pedometers) can increase adherence to such a regimen. ${ }^{41}$ The intervention has been shown to reduce weight gain in families with overweight children, 19,42 and its short-term efficacy has been demonstrated in a study of 116 overweight adults. ${ }^{43}$ Such approaches can produce results without the feelings of burden and restriction associated with more stringent interventions.

\section{Conclusion}

The global obesity problem has arisen from small imbalances in energy intake and expenditure that have accumulated over time. The failure of 
current interventions to achieve any meaningful, long-term results in combating obesity could reflect a failure to appreciate the physiologic processes underlying energy balance. New approaches that consider how the energy balance system works should replace the existing focus on widespread food restriction and weight loss. There is a need to educate the public on the concept of energy balance and to help them develop the cognitive skills required to counter the tendency for overeating and sedentary behaviour. The concept of regulated and unregulated zones of energy balance can explain the obesity epidemic among the increasingly sedentary population.

However, relatively small changes in energy intake and expenditure can arrest weight gain in most people. By increasing physical activity in the population, more people will move to the regulated zone of energy balance and as a result will have greater bodyweight control. Only by addressing the prevention of weight gain can the obesity epidemic be reversed.
1. Finkelstein EA, Trogdon JG, Cohen JW, et al., Annual medical spending attributable to obesity: Payer-and service-specific spending attributable to obesity: Payer-and ser.

Finkelstein EA, Trogdon JG, Cohen JW, et al., Annual medical pending an to spending attributable to obesity: payer-and service-sp estimates, Health Afr $M$ mo tregal KM, Carroll MD, Ogdn CL, et al, 2002;288:1723-7.

Ogden CL, Carroll MD, Kit BK, et al. Prevalence of obesity in the United States, 2009-2010, NCHS Data Brief, 2012:18. the United States, 2009-2010, NCHS Data Brief, 2012;1-8,

6. Hankinson, a avigl, high physical activity level over 20 years and weight gain, IAMA, 2010:304:2603-10.

Williamson DF, Madans J, Anda RF, et al., Recreational physical activity and ten-year weight change in a US nation physical act chy and J And is Hill $\perp$, wyatt HR, Reed GW, et al, Obesity and the environment: where do we go from here? Science, 2003:299:853-5

9. Hafekost K, Lawrence D, Mitrou F, et al., Tackling overweight and obesity: does the public health message match the science?, BMC Med, 2013:11:41.

0. Hill JO, Wyatt HR, Peters JC, Energy balance and obesity, Circulation, 2012:126:126-32.

1. Hill JO, Commerford R, Physical activity, fat balance, and energy balance, Int J Sport Nutr, 1996;6:80-92.

12. Lustig R, The Efferent Arm of the Energy Balance Regulaton Pathway: Neuroendocrinology and Pathology Energy Metabolism and Obesity Contemporary Endocrinology, P A Donohoue (Ed.), Totowa, NJ: Humana Press Inc., 2008;69-85.

13. Martin CK, Heilbronn LK, de Jonge L, et al., Effect of calorie restriction on resting metabolic rate and spontaneous physical activity, Obesity (Silver Spring), 2007;15:2964-73.

14. Hill JO, Peters JC, Wyatt HR, Using the energy gap to address obesity: a commentary, I Am Diet Assoc, 2009;109:1848-53.

15. Mayer J, Roy P, Mitra KP, Relation between caloric intake, body weight, and physical work: studies in an industrial male population in West Bengal, Am I Clin Nutr, 1956;4:169-75.

16. Mayer J, Marshall NB, Vitale JJ, et al., Exercise, food intake mice, Am I Physiol, 1954:177:544-8.

17. King NA, Horner K, Hills AP, et al., The interaction between exercise, appetite, and food intake: implications for weight control, American Journa of Lifestyle Medicine published online February 6 2013 (available at: $h$ ttp //ajl. sagepub.com/content/ early/2013/02/05/1559827613475584.abstract).

18. Schubert MM, Desbrow B, Sabapathy S, Leveritt M, Acute Screrce and subsequent intake: a meta-analysis, Appetite, 2013:63:92-104

19. Flatt JP, Misconceptions in body weight regulation: implications for the obesity pandemic, Crit Rev Clin Lab Sci, 2012;49:150-65.

20. Swinburn B, Sacks G, Ravussin E, Increased food energy supply is more than sufficient to explain the US epidemic of obesity. Am J Clin Nutr, 2009:90:1453-6.

21. Besson H, Ekelund U, Luan J, et al., A cross-sectional analysis of physical activity and obesity indicators in European participants of the EPIC-PANACEA study, Int 1 bes (Lond) 2009;33:497-506.

22. French SA, Jeffery RW, Forster JL, et al., Predictors of weight change over two years among a population of working adults: the Healthy Worker Project, Int $J$ Obes Relat Metab Disord, 1994;18:145-54.

23. May AM, Bueno-de-Mesquita HB, Boshuizen $\mathrm{H}$, et al., Effect of change in physical activity on body fatness over a 10-y period in the Doetinchem Cohort Study. Am I Clin Nutr, 2010;92:491-9.

24. Waller K, Kaprio J, Kujala UM, Associations between longterm physical activity waist circumference and weight gain: a 30-year longitudinal twin study, Int I Obes (Lond), 2008;32:353-61.

25. Ham SA, Kruger J, Tudor-Locke C, Participation by US adults in sports, exercise, and recreational physical activities, Phys Act Health, 2009; 6:6-14.

26. Bassett DR, Schneider PL, Huntington GE, Physical activity in an Old Order Amish community. Med Sci Sports Exerc, 2004;36:79-85

27. Brown WJ, Williams $L$, Ford $J H$, et al., Identifying the energy gap: magnitude and determinants of 5-year weight gain in midage women, Obes Res, 2005:13:1431-41

Blundell JE, King NA, Physical activity and regulation of food intake: current evidence, Med Sci Sports Exerc, 1999;31:S573-83.

29. Stubbs RJ, Hughes DA, Johnstone AM, et al., A decrease in physical activity affects appetite, energy, and nutrient balance in lean men feeding ad libitum, Am I Clin Nutr. 2004;79:62-9.

30. Rodearmel SJ, Wyatt HR, Stroebele N, et al., Small changes in dietary sugar and physical activity as an approach to preventing excessive weight gain: the America on the Move family study, Pediatrics, 2007;120:e869-79.

31. Sorensen $\mathrm{Tl}$, Conference on "Multidisciplinary approaches to nutritional problems". Symposium on "Diabetes and health".
Challenges in the study of causation of obesity, Proc Nutr Soc, 2009;68:43-54.

32. Dulloo $A G$, Jacquet I, Adaptive reduction in basal metabolic rate in response to food deprivation in humans: a role for feedback signals from fat stores, Am J Clin Nutr. 1998;68:599-606.

33. Schwartz MW, Woods SC, Porte D, Jr., et al., Central nervous system control of food intake, Nature 2000:404:661-71. Wing RR, Hill JO, Successful weight loss maintenance, Annu Rev Nutr, 2001:21:323-41.

35. Jeffery RW, Drewnowski A, Epstein LH, et al., Long-term maintenance of weight loss: current status, Health Psychol 2000:19:5-16.

36. Mann T, Tomiyama AJ, Westling E, et al., Medicare's search for effective obesity treatments: diets are not the answer, Am Psychol, 2007;62:220-33.

37. Hall KD, Sacks G, Chandramohan D, et al., Quantification of the effect of energy imbalance on bodyweight, Lancet, 2011:378:826-37.

38. Wang YC, Gortmaker SL, Sobol AM, et al., Estimating the energy gap among US children: a counterfactual approach, Pediatrics, 2006;118:e1721-33.

39. Mozaffarian D, Hao T, Rimm EB, et al., Changes in diet and lifestyle and long-term weight gain in women and men, N Engl J Med, 2011;364:2392-404.

40. Hill JO, Can a small-changes approach help address the obesity epidemic? A report of the Joint Task Force of the American Society for Nutrition, Institute of Food Am J Clin Nutr, 2009;89:477-84.

41. Wyatt HR, Peters JC, Reed GW, et al., Using electronic step counters to increase lifestyle physical activity: Colorado on the Move, J Phys Act Health, 2004:1:181-91.

42. Rodearmel SJ, Wyatt HR, Barry MJ, et al, A family-based approach to preventing excessive weight gain, obesity (Silver Spring), 2006:14:1392-401.

43. Stroebele N, de Castro JM, Stuht J, et al., A small-changes approach reduces energy intake in free-living humans, $J$ Am Coll Nutr, 2009:28:63-8.

44. Di Pietro L, Dziura J, Blair SN, Estimated change in physical activity level (PAL) and prediction of 5-year weight change in men: the Aerobics Center Longitudinal Study, Int I Obes Relat Metab Disord, 2004;28:1541-7.

45. Wagner A, Simon C, Ducimetiere P, et al., Leisure-time physical activity and regular walking or cycling to work are associated with adiposity and $5 \mathrm{y}$ weight gain in middleaged men: the PRIME Study, Int I Obes Relat Metab Disord, 2001;25:940-48. 